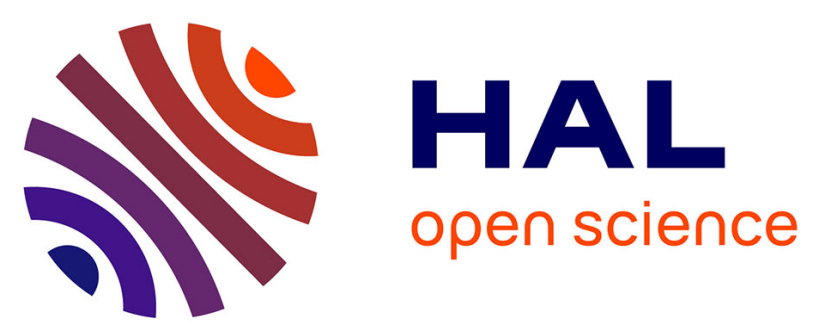

\title{
MINORITY CARRIER LIFETIME AND POTENTIAL BARRIER HEIGHT IN POLYCRYSTALLINE SILICON : EFFECTS OF LOW TEMPERATURE ANNEALINGS AND NEUTRON IRRADIATION
}

\author{
D. Bielle-Daspet, M. Roux, J. Farah
}

\section{To cite this version:}

D. Bielle-Daspet, M. Roux, J. Farah. MINORITY CARRIER LIFETIME AND POTENTIAL BARRIER HEIGHT IN POLYCRYSTALLINE SILICON : EFFECTS OF LOW TEMPERATURE ANNEALINGS AND NEUTRON IRRADIATION. Journal de Physique Colloques, 1982, 43 (C1), pp.C195-C1-101. 10.1051/jphyscol:1982114 . jpa-00221770

\section{HAL Id: jpa-00221770 https://hal.science/jpa-00221770}

Submitted on 1 Jan 1982

HAL is a multi-disciplinary open access archive for the deposit and dissemination of scientific research documents, whether they are published or not. The documents may come from teaching and research institutions in France or abroad, or from public or private research centers.
L'archive ouverte pluridisciplinaire HAL, est destinée au dépôt et à la diffusion de documents scientifiques de niveau recherche, publiés ou non, émanant des établissements d'enseignement et de recherche français ou étrangers, des laboratoires publics ou privés. 
JOURNAL DE PHYSIQUE

Colzoque C1, supplément au $n^{\circ} 10$, Tome 43, octobre 1982

page $\mathrm{Cl}-95$

\title{
MINORITY CARRIER LIFETIME AND POTENTIAL BARRIER HEIGHT IN POLYCRYSTALLINE SILICON : EFFECTS OF LOW TEMPERATURE ANNEALINGS AND NEUTRON IRRADIATION+
}

\author{
D. Bielle-Daspet, M. Roux* and J. Farah
}

Laboratoire d'Automatique et d'Analyse des systèmes du C.N.R.S., 7, Avenue du Colonel Roche, 31400 Toulouse, France

*C.E.R.T., D.E.R.T.S., 2, Avenue Edouard Belin, 31055 Toulouse Cedex, France

Resumé. - Les effets de recuits à température $\mathrm{T} \leqslant 450^{\circ} \mathrm{C}$, sous argon ou sous hydrogène, et d'irradiations par neutrons de $14^{\circ} \mathrm{MeV}$ sont comparés en terme de durée de vie volumique $\tau_{v}$ des porteurs minoritaires et de hauteur $\emptyset_{B}$ des zones de barrière de potentiel. Les mesures sont essentiellement rêalisées par photocourant et photoconductivité transitoires, et par caractéristiques $I(V, T)$, dans des rubans RAD à gros grains ( $C Z$, dopé $B, i \Omega, \mathrm{cm}$ ).

Les résultats montrent que les recuits, qu'ils soient réalisés sous argon ou sous hydrogène, affectent peu $Z_{v}(\sim 1$ à $0,5 \mu s)$. I1 en est de meme de $\emptyset_{B}$ $(0,10$ à $0,20 \mathrm{eV})$. Par contre, les effets dés zones de barrière $\emptyset_{\mathrm{B}}$ sur la conduction ne suivent le modèle de doubles barrières de Schottky que dans les échantillons non recuits sous hydrogène : en passivant les joints près de la surface, I'hydrogène rend les effets des zones de barrière restantes équivalents à ceux de zones électriquement isolantes.

La sensibilité du matériau aux irradiations s'avère également liée à la sensibilité des zones de barrière de potentiel :

- la dégradation de Zuest équivalente à celle obtenue dans un monocristal ;

- les variations de $\emptyset_{B}$ entrainent une modification importante de la conduction pour des doses où la conductivité d'un monocristal n'est pas affectée.

Abstract. - The effects of annealing, at temperatures $\leqslant 450^{\circ} \mathrm{C}$ under argon or hydrogen atmosphere, and of $14 \mathrm{MeV}$ neutron irradiation on bulk lifetime $\tau_{v}$ of minority carriers and height $\emptyset_{B}$ of the potential barrier regions are compared. The measurements essentially involve transient photocurrent and photoconductivity responses, and $\mathrm{I}(\mathrm{V}, \mathrm{T})$ characteristics, of samples from large grain R.A.D. ribbons (CZ silicon, boron doped, 1.2.cm).

The results show that the low temperature annealing with argon or hydrogen scarcely modifies both the $\tau_{v}(1$ to $0,5 \mu \mathrm{s})$ and $\phi_{B}(\sim 0.10$ to $0.20 \mathrm{eV})$ values. But the effects of the regions with potential barriers $D_{B}$ on the material conductivity only agree with the double-Schottky barrier model when the samples have not been annealed under hydrogen : by passivating grain boundaries near the sample surface, hydrogen makes the effects of the remaining barrier regions analoguous to the effects of insulating zones.

Following neutron irradiation the behaviour of the electrical properties of the material is again strongly related to the behaviour of the potential barrier regions :

- the degradation of $\tau_{v}$ appears comparable to the degradation observed in single-cristalline samples;

- the variations of $\emptyset_{\mathrm{B}}$ are responsible for the change in sample conduction which is observed at the low irradiation doses where single-cristal conductivity is not affected.

+ work performed under collaboration with P.I.R.S.E.N. 
Grain boudaries are known to change the conduction properties of polycristalline materials : as these boudaries are surrounded by potential barriers of height $\emptyset_{\mathrm{B}}$, material conduction is then regulated by the potential barrier regions, i.e., by the effects of the barriers on the material free carriers. It is thus of major interest to know what changes in the potential barrier appear due to the treatments (thermal annealing, particle irradiation,...) the material has been subjected to, and to correlate these changes with those induced in the charge transport properties of the sample, especially conductivity and free carrier lifetime.

The cases of low temperature annealings $\left(T \leqslant 450^{\circ} \mathrm{C}\right)$ and of room temperature irradiation by $14 \mathrm{MeV}$ neutrons up to flux of $10^{13} \mathrm{n} \cdot \mathrm{cm}^{-2}$ are investigated in the present paper. The low temperature annealings allow to anneal the material point defects (vacancy-impurity complexes, interstitials.../1/) and, in the presence of hydrogen, to saturate the dangling bonds in the grain boundary regions $/ 2 /$. On the other hand, irradiation by particles such as $14 \mathrm{MeV}$ neutrons is a way for introducing vacancytype complexes $V^{2}, V-T .$. : the effects of defect introduction in polycristalline material and in single-cristalline material may be compared.

The work has been performed on single-layered polycristalline silicon with large grains of $\geqslant 100 \times 300 \mu \mathrm{m}^{2}, 60-80 \mu \mathrm{m}$ thick, elaborated for photovoltaic purpose from $\mathrm{CZ}$ boron doped $18 \mathrm{~cm}$ silicon, on carbon substrate, by the R.A.D. technique/3/. A dozen of samples issued from a same technological process have been used in the study.

\section{ELECTRICAL PP.OPERTIES : MEASUREMENTS AND BEHAVTOUR}

The electrical properties dealt with are the concern of the charge transport allong the pulling axis of the polycristalline ribbon.

Two measurement techniques are involved :

- I(V) characteristics versus measurement temperature $/ 4 /$;

- electrical responses to transient excitation by $1.06 \mu \mathrm{m}$ laser pulse of $40 \mathrm{~ns}$ duration : (i) decay of the photoconductivity responses $\Delta V(t) / 5 /$, (ii) ways of decay of the diffusion photocurrent $i_{D}(t)$ associated to the free minority carriers $/ 6,7 /$.

Following the analysis given in a previous paper $/ 8 /$, the effect of the grain boundary regions on the $I(V)$ characteristic of such a material may be schematized using two current components (figure 1) :

$$
\mathrm{I}=\mathrm{I}_{1}+\mathrm{I}_{2}
$$

The component $I_{1}$ is the electrical current crossing a double barrier of Schottkydiode with area $S$. This component is given, under low pertubation conditions, by :

$$
I_{1}=S J_{S} \operatorname{sh}\left(\frac{g V_{A}}{2 m k T}\right)
$$

where $\mathrm{m}$ is the ideality factor of the Schottky barrier, $V_{A}$ the applied voltage accross the double barrier of Schottky and $J_{S}$ the density of the saturation current.

The component $I_{2}$ is the electrical current through the possible discontinuities of the boundary represented by the shunt resistance $R_{\text {sh }}$ :

(3) $\quad \mathrm{I}_{2}=\mathrm{V}_{\mathrm{A}} / \mathrm{R}_{\mathrm{sh}}$

where $\mathrm{V}_{\mathrm{A}}$ corresponds to (cf. figure 1 ) :

(4) $\quad V_{A}=\frac{V}{N}-I R_{S}$

if $\mathrm{V}$ is the voltage applied accross the $\mathrm{N}$ modulus "grain-grain boundary" of the sample. Using the thermoinic emission-diffusion theory /9/, the current density $J_{s}$ may be written as follows :

$$
J_{S}=A^{++} T^{2} \text { exp. }\left(-\frac{E_{F j}}{k T}\right)
$$

$E_{F j}$ is the Fermi level inside the boundary region such as

$$
\text { (6) } \quad E_{F j}=\emptyset_{B o}+\left(E_{F v}-E_{V}\right)
$$

$\emptyset_{B O}$ being the grain bqundary potential barrier height and $E_{F v}$ the Fermi level inside the grain. In (5), $A^{t}$ is the effective Richardson constant :

$$
\mathrm{A}^{\star *}=---\mathrm{f}_{\mathrm{T}}-\frac{\mathrm{f}_{\mathrm{f}}}{\mathrm{f}_{\mathrm{T}}} \mathrm{pr}_{\mathrm{pr}}-\mathrm{v}_{\mathrm{R}} / \overline{v_{\mathrm{D}}}
$$


if we note by $A^{*}$ the Richardson constant, $f_{T}$ the tunneling carrier probability, $f_{p r}$ the overall probability of the carrier backdiffusion, $v_{R}$ the effective recombination velocity of the carriers entering into the barrier region and $v_{D}$ the velocity of these carriers inside this region (usually $v_{D}>v_{R}$ ). For large enough values of $v$ so that $V_{A} \gg m k T / q$, the general expression of the current thus obey the relation :

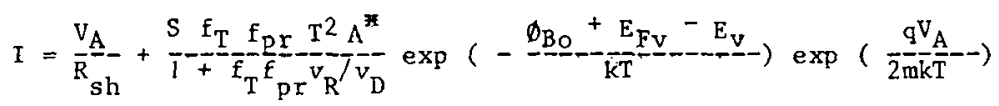

The plot of $\log I$ versus $V$ leads to $J_{s}$ at given temperature T. Measurements at various temperatures allow to study the variation of $\log \left(\mathrm{J}_{S} / \mathrm{T}^{2}\right)$ versus $1 / T$ (figure 2 ) and we obtain a value $\emptyset_{\mathrm{B}}$ of the potential barriers which is an averaged value for the potential barriers inside the sample.

The values of $\emptyset_{\mathrm{Bo}}$ obtained in the as-grown samples are given in Table 1 .

\begin{tabular}{|c|c|c|c|}
\hline$I(V)$ & $\begin{array}{c}\emptyset_{B \rho} \\
(\mathrm{ev})\end{array}$ & $\tau_{V(\mu s)}\left(i_{p}\right)$ & $\tau_{(\mu s)}^{\left(\Delta V_{\sigma}\right)}$ \\
\hline$I_{1}$ & $\begin{array}{c}0.15 \\
(0.12-0.18)\end{array}$ & $0.7-0.8$ & $\left(\tau_{\sigma}\right) 15-30$ \\
\hline
\end{tabular}

Table 1: I (V) behaviour, barrier height $\emptyset_{\mathrm{B}}$, bulk minority carrier lifetime $\tau_{v}$ and time constant $\tau_{\sigma}$ at the decay beginning of the photoconductivity response $\Delta \mathrm{V}_{\sigma}$ in the as-grown polycristalline samples.

At the lowest temperatures (cf. figure 2), the encrease in $\log \left(\mathrm{J}_{S} / \mathrm{T}^{2}\right.$ ) may be explained by carrier tunneling through the boundaries $/ 9,10 /$ due to the encreased effect of $\mathrm{f}_{\mathrm{T}}$-see (7)- when $\mathrm{T}$ decreases $/ 9 /$.

Transient diffusion photocurrent $i_{D}(t)$ is due to the excess minority carriers (electrons in our case) created in the sample by uniform bulk photoexcitation and collected by diffusion.

With thin samples, this method allows to study both $\tau_{V}$ ( bulk carrier lifetime) at the decay beginning, and $\tau_{G}$ (due to surface recombination, $\tau_{G} \propto \mu_{n}^{-i}$ ) at the end of the decay $/ 6 /($ figure 3 ).

The transient photoconductivity response $\Delta V(t)$ is measured under constant polarization current. It leads to the variation in conductivity $\Delta \sigma(t)$ induced by the excess electrons and holes created in the sample. Thus the $\Delta V_{\sigma}(t)$ response takes into account the density-mobility product, $p(t) \mu_{p}(t), n(t) \mu_{n}(t)$, for these carriers. In the case of a polycristalline ( $P$ type) material, because of the charge conduction mechanism involved, two components have to be distinguished in a photoconductivity response /5/ : one is related to the decrease in the potential barrier height $\Delta \phi_{\mathrm{B}}$ induced by the excess minority (electron) carriers which have been trapped inside the potential barrier regions; the other one comes from the free excess carriers $\Delta \mathrm{n}, \mathrm{p}(t)$ (where $\Delta m(t)<\Delta p(t)$ produced inside the grains. Depending on the mechanism which dominates the charge carrier transport in the polycristalline sample, behaviours of a signal may be summarized as follows :

- When charge conduction is dominated by carrier transport through the potential barrier regions (i.e., $I(V)$ ruled by $I_{1}$ component in (1)), photoconductivity decay $\tau_{\sigma}$ is controlled by the variation in the majority carrier mobility $\mu_{p}(t)$ and the return to equilibrium of the potential barrier variation $\Delta \phi_{B}(t)$ because trapped minority carriers are emitted over the $\emptyset_{\mathrm{BO}}-\Delta \emptyset_{\mathrm{B}}(t)$ barrier. Because the photoconductivity measurements are performed under low polarization conditions, expression of the majority carrier mobility can be deduced from expression (8) written for $v_{A} \ll<2 m k T / q$. It gives : 


$$
\mu_{p}(t)=\mu_{p o} \exp \left(-\Delta \emptyset_{B}(t) / k T\right)
$$

with

$$
\mu_{\text {po }}=\frac{A^{x * T} T}{2 \operatorname{kmn} V} \exp \left(-\emptyset_{B O} / k T\right)
$$

and

$$
p(t)=N_{Y} \exp \left(-\frac{E_{E V}{ }^{*}-E_{Y T}}{k T}\right)=p_{0}+\Delta_{p}(t)
$$

- On the contrary, when charge conduction is defined by ohmic process i.e., I(V) given by the $I_{2}$ component in (1), photoconductivity decay is controlled by the recombination $\tau_{v}$ of the excess electrons and holes $\Delta m, p(t)$. End of the response may then show a tail, due to the contribution of trapped minority carriers.

\section{RESULTS}

\section{Thermal annealing with hydrogen or argon}

The electrical properties obtained with samples annealed for periods of 5 minutes under hydrogen $\left(\mathrm{T}=450^{\circ} \mathrm{C}\right)$ or argon $\left(\mathrm{T} \leqslant 400^{\circ} \mathrm{C}\right)$ are sumarized in Table 2.

\begin{tabular}{|l|c|c|c|c|}
\hline & $I(V)$ & $\emptyset_{B O(e v)}$ & $\begin{array}{c}\tau_{V}\left(i_{B}\right) \\
(\mu s)\end{array}$ & $\begin{array}{c}\tau\left(\Delta V_{\sigma}\right) \\
(\mu s)\end{array}$ \\
\hline$H_{2}$ annea1 & $\sim I_{2}$ & - & $0.8-1.0$ & $\left(\tau_{V}\right) 1.0$ \\
\hline$A_{r}$ annea1 & $I_{1}$ & 0.18 & 0.5 & $\left(\tau_{\sigma}\right) 20$ \\
\hline
\end{tabular}

Table 2 : Parameters of the charge carrier transport in the polycristalline samples following thermal annealing with hydrogen or argon at $\mathrm{T}_{\mathrm{r}}=450$ or $400^{\circ} \mathrm{C}$ (annealing duration at $\mathrm{T}_{\mathrm{r}}$ is five minutes)

These properties are deduced from the characteristics $I(V, T)$ and the transient photoresponses $\Delta V_{\sigma}(t), i_{D}(t)$ at room temperature as previously described in Section $I$. By comparison with the electrical properties of the as-grown samples (Cf. Table 1), the first result to note is the effect of the annealing with argon. Both the $\mathrm{I}(\mathrm{V}, \mathrm{T})$ characteristics and the photoconductivity responses $\Delta V_{\sigma}(t)$ stay then dominated by the component associated with carrier transport through a double Schottky barrier. Moreover, an increase of the corresponding potential barrier height $\emptyset_{\mathrm{BO}}$ clearly appears. On the contrary, following anneal at $400^{\circ} \mathrm{C}$, the free carrier lifetime $\zeta_{v}$ is little modified (figure $5 a$ ). But the minority carrier mobility $\mu_{m} \propto \tau_{G}{ }^{-1}$ should be increased by a factor 2 (figure 5b) : this well agrees with the opposite effects that a potential barrier has on the majority and minority carrier mobilities. Effect of thermal annealing with hydrogen is strongly different since carrier conduction with ohmic character then becomes dominant in the $I(V)$ characteristics (see $I_{2}$ in (I)). Simultaneously, the appearancy of a strong component from free carriers $\Delta m, p(t)$ is observed in the photoconductivity responses.

\section{Neutron imadiation effects}

The variations which have been measured versus neutron flux are illustrated in the figures $4 \mathrm{~b}, 5$ and 6 for, respectively : (i) $\phi_{B O}, \tau_{V}$ and $\tau_{G} \times \mu_{n}{ }^{-1}$, in the cases of an as-grown sample and of a sample previously annealed up to $400^{\circ} \mathrm{C}$ with argon, and $(i i)$ for $\tau_{v}$ in the case of P-type monocristalline and polycristalline samples irradiated simultaneous $1 \mathrm{y}$.

General behaviour of the results obtained with the polycristalline samples shows that the degradation rate of the minority carrier lifetime stays anslogous to the degradation rate measured in monocristalline materials of comparable resistivity. 
But, due to variations in the values of $\emptyset_{\mathrm{B}}$, notable change in carrier conductivity may appear in the polycristalline materials when they are irradiated by neutron fluxes at which the conductivity of ronocristalline samples is not affected (see results at $D=10^{12} \mathrm{n} \cdot \mathrm{cm}^{-2}$, for instance),$\pi$

Furthermore, it is to notice that, under irradiation an as-grown sample shows a. higher degradation rate of $\tau_{r}$ and a lower modification of conduction than a sample previously annealed up to $400^{\circ} \mathrm{C}$ with argon.

SIMANAFY

There are the potential barrier zones which are sensitive to the constraints; and, thus, they rule the electrical behaviour of a large grain polycristal.

Indecd, the conductivity variations are always associated to the potential barriers zones after the annealing under hydrogen or argon atmosphere.

It is the same for the neutron irradiations in the low flux range : they affect not inly the carrier lifetime (as in monocristalline sample case), but also the sample electrical conductivity due to the impact of the irradiation on the potential barrier heights.

\section{BIBLIOGRAPHY}

1 CORBETT, J.W., BOURGOIN, J.C., CHENG, L.J., CORELLI, J.C., LEE, Y.H., MOONEY, P.M. and WELGEL, C., Inst. Phys. Conf. Ser, 31 (1977) 1

2 GINLEY, D.S. and HAALANG, D.M., Appl. Phys. Lett., 39 (1981) 271

3 BET.OUET, C. BELIN, C., SCHNEIDER, J., PAULIN, J., 3è P.V. SOZaT En. Conf., Cannes $(1.980)$

4 TARNG, M.L., J. Appl. Phys., 49 (1978) 4069

5 ROUX, M. and BLELLE-DASPET, D., Rev. Phys. App Z, , 16 (1981) 497

6 BIELLE-DASPET, D. and GASSET, G., Solid. State Electron., 21 (1978) 1219

7 BIEllF,-DASPET, D., JOHAN, A. and ESPIOUSSAS, F., Rev. Phys. Appl., 15 (1980) 945

8 JOHAN, A. AYERT.A, J. BIEI,LE-DASPET, D. ROCHER, A. and FONTAINE, C. , $2 e$ P.V. SOlar En. Conf., Berlin (1979)

9 See for instance SZE, S.M., Physics of semiconductors devices, P. Wiley and Son N.Y.), 1970, PP. 382-390

10 SEAGER, C.H. and PIKE, G.E., Appl. Phys. Lett., 40 (1982) 471

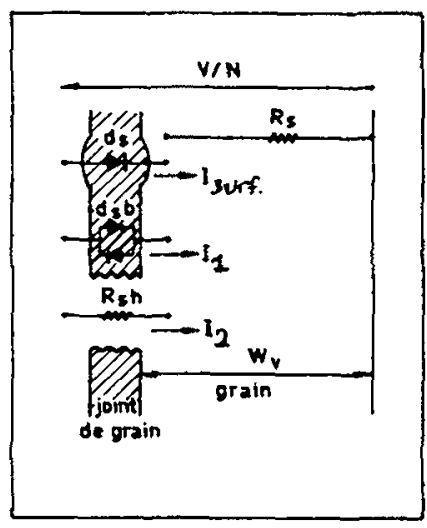

Figire 1 Equivalent electrical schema of a "grain-grain boundary" moculus in a polycristalline material

* Simultaneously, the DLTS spectra also differ from the response of single-cristalline specimen : the dominant energy levels are located at $\mathrm{Ev}+0.40$ and $0.16 \mathrm{eV}$ in the single-cristalline and polycristalline materials, respectively, after irradiation. 

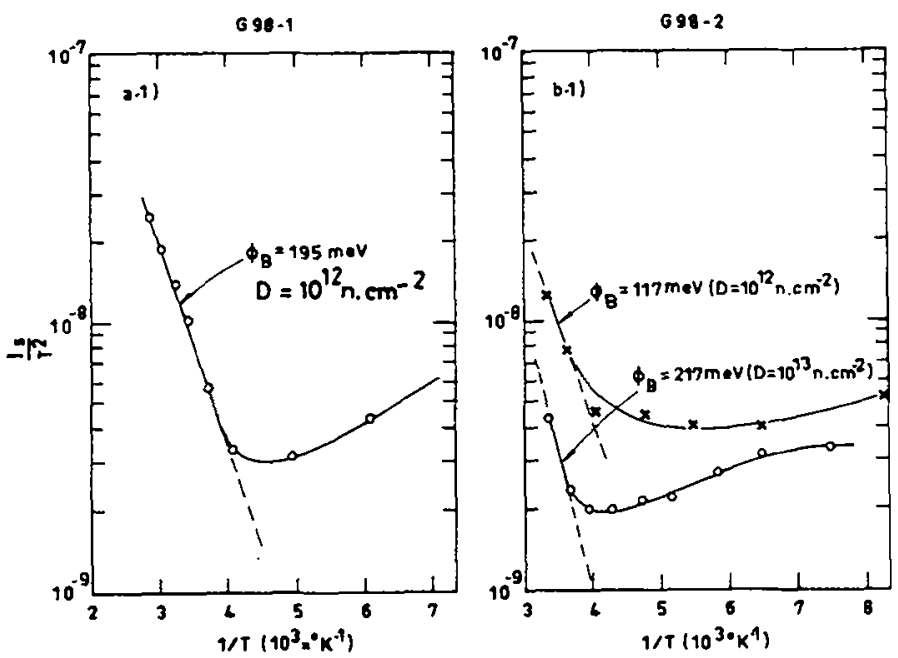

Figure 2 The $\log \left(\mathrm{J} S / \mathrm{T}^{2}\right)$ for $V>>\frac{k T}{\mathrm{~T}}$, plotted versus the reverse temperature $1 / T$ for both samples $G 98-1$ and $G 98-2$ at two irradiation fluxes $\mathrm{D}=10^{12} \mathrm{\pi} . \mathrm{cm}-2$ and $\mathrm{D}=1013 \mathrm{n} . \mathrm{cm}^{2}$

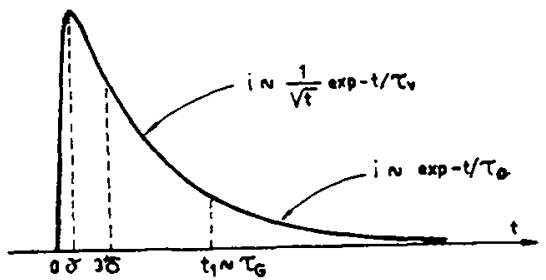

Figure 3 Shape of a diffusion photocurrent response created by brief penetrating excitation of duration $\delta / 6 /$

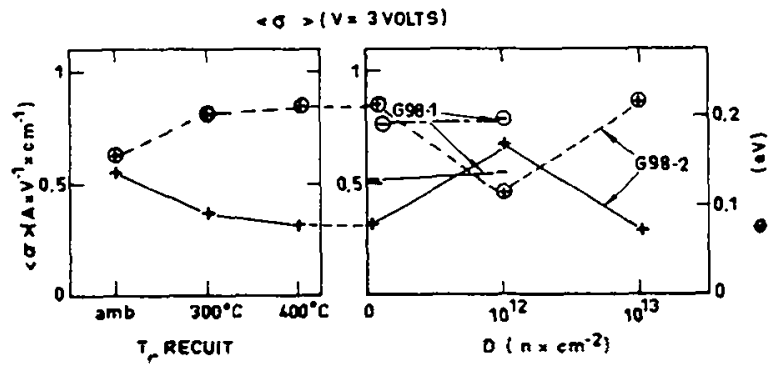

Figure 4 Conductivity $\langle J\rangle(+,-)$ and potantial barrier heights $\emptyset_{\mathrm{B}}(\hat{\mathrm{t}}, \hat{\epsilon})$ plotted versus the annealing temperature $\mathrm{T}_{\mathrm{r}}$ and the irradiation dose $\mathrm{D}$.

$\langle\sigma\rangle$ Is deduced from the I/V ratio measured under low values

of the polarisation-cf. (1) to (3)Unannealed and argon-annealed samples G98-1 and G98-2.

Annealing duration at $T_{r}$ is five minutes. 
(a)

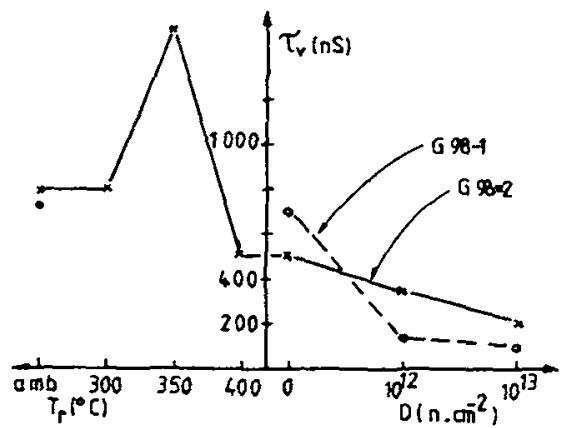

(b)

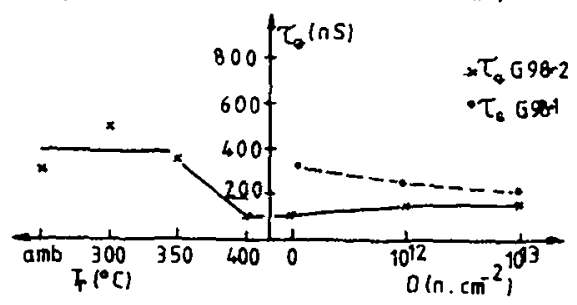

Figure 5 Evolution of (a) ? $v$, bulk carrier lifetime, and (b) $C_{\text {, }}$, lifetime due to surface recombination, versus anneal ing temperature $\mathrm{T}_{r}$, and irradiation dose $\mathrm{D}$.

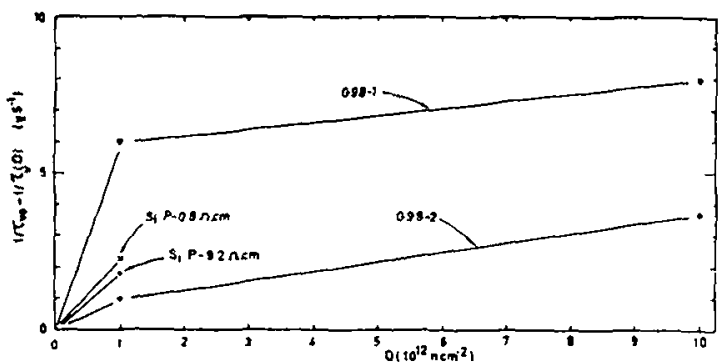

Figure 6 Degradation rate $\left(\tau^{-1}-\tau(p)^{-1}\right)$ versus irradiation dose $D$ for polycristallines samples G98-1 and co8-2 (G98-2 sample which is annelaed at $400^{\circ} \mathrm{C}$ before irradiation) and $1 \Omega . \mathrm{cm}$ and $10 \Omega . \mathrm{cm}$ monocristalline samples. 